\title{
An environmental control box for serial crystallography enables multi-dimensional experiments
}

\author{
Pedram Mehrabi ${ }^{1,2 *}$, David von Stetten ${ }^{3}$, Jan-Philipp Leimkohl ${ }^{4}$, Friedjof Tellkamp ${ }^{4}$ \\ and Eike C. Schulz ${ }^{1,2 *}$
}

${ }^{1}$ Hamburg Centre for Ultrafast Imaging, Universität Hamburg, HARBOR, Luruper Chaussee 149, 22761 Hamburg, Germany

${ }^{2}$ Max-Planck-Institute for Structure and Dynamics of Matter, Department for Atomically Resolved Dynamics, Luruper Chaussee 149, 22761 Hamburg, Germany

${ }^{3}$ European Molecular Biology Laboratory (EMBL), Hamburg Unit c/o Deutsches Elektronen Synchrotron (DESY),

Notkestrasse 85, D-22603 Hamburg, Germany.

${ }^{4}$ Max-Planck-Institute for Structure and Dynamics of Matter, Scientific Support Unit Machine Physics, Luruper Chaussee 149, 22761 Hamburg, Germany

*corresponding authors:pedram.mehrabi@uni-hamburg.de; eike.schulz@uni-hamburg.de

\begin{abstract}
We present a new environmental enclosure for fixed-target, serial crystallography enabling full control of both the temperature and humidity. While maintaining the relative humidity to within a percent, this enclosure provides access to $\mathrm{X}$-ray diffraction experiments in a wide temperature range from below $10{ }^{\circ} \mathrm{C}$ to above $80^{\circ} \mathrm{C}$. Coupled with the LAMA method, time-resolved serial crystallography experiments can now be carried out at truly physiological temperatures, providing fundamentally new insight into protein function. Using the hyperthermophile enzyme xylose isomerase, we demonstrate changes in the electron density as a function of increasing temperature and time. This method provides the necessary tools to successfully carry out multidimensional serial crystallography.
\end{abstract}

Keywords:

serial-crystallography, SSX, multi-temperature crystallography, time-resolved crystallography, multidimensional crystallography 


\section{Introduction}

Life has evolved to occupy a wide range of different environmental niches, ranging from arctic deserts to the hot ponds at Yellowstone ${ }^{1}$. Biochemical, bioinformatics and structural studies over many years have provided insight into how protein folds and function are maintained across, for example, such extreme ranges of temperature ${ }^{2,3}$. Although enzymes operate over a wide range of temperatures, the vast majority of protein structural information, from X-ray crystallography and cryo-EM, has been acquired at cryogenic temperatures, using flash cooling to trap their structures close to the native, functional state. The main reason for data-collection at cryo-temperatures is to reduce the rate of radiation damage ${ }^{4}$. However, flash-cooling can lead to structural artefacts that are absent at ambient temperatures and that this may affect biological interpretation of the data ${ }^{5-8}$. In addition, as proteins are not not single unique structures, but rather an ensemble of states that fluctuate around an energetic ground-state ${ }^{9}$, the conformational dynamics of enzymes are directly correlated with their catalytic rate ${ }^{10}$, and these dynamics are intimately linked to temperature.

This mismatch between standard data collection temperatures and the optimal temperature for function thus becomes an acute problem when carrying out time-resolved structural studies that seek to provide detailed insight into catalytic mechanisms and allosteric regulation. Although, with the advent of serial crystallographic methods at synchrotrons and XFELs (SSX, SFX), time-resolved structural studies are under going a resurgence, the majority of such experiments are still carried out at ambient temperatures $\left(4^{\circ} \mathrm{C}-25^{\circ} \mathrm{C}\right)$, regardless of the actual temperature optimum of the protein under study ${ }^{11,12}$.

A notable exception is the pioneering work on photoactive yellow (PYP) protein, where time-resolved data were collected from $-40{ }^{\circ} \mathrm{C}-70^{\circ} \mathrm{C}$, so called 5D-crystallography ${ }^{13,14}$. Unfortunately, the considerable technological difficulties of this seemingly simple experiment have so far prevented routine structure determination as as function of physiologically relevant temperatures.

To address this challenge we have developed an environmental control system for serial crystallography that enables the precise control of humidity and temperature over a a large temperature window from $<$ $10^{\circ} \mathrm{C}$ to $>80^{\circ} \mathrm{C}$. This temperature window is large enough to encompass physiologically relevant temperatures of hyperthermophile enzymes. Via full compatibility with our previously described tools for reaction initiation by rapid mixing (LAMA) ${ }^{15}$, this system permits multi-temperature, time-resolved serial crystallography experiments (5D-SSX), provided the crystals are stable at the temperatures of interest. These experiments enable a unique view into a hitherto inaccessible realm of protein function. To demonstrate the power of this approach we have used the hyperthermophile enzyme xylose isomerase (XI), which has an activity optimum at a temperature of $\sim 80^{\circ} \mathrm{C}^{16}$. 


\section{Results}

\section{Environmental control box design}

A hallmark of protein crystals is their large solvent-content, which is typically in the range between $40 \%$ and $70 \%$ of the crystal volume. An advantage of this property is that proteins generally retain their function even in the crystalline state ${ }^{17,18}$. A commonly known disadvantage is, however, their sensitivity to changes in environmental humidity, which in addition to the higher rates of radiation damage associated with higher temperatures makes routine data collection at even ambient temperatures a difficult task. Starting with traditional wax-enclosed glass capillaries, several solutions have been developed to maintain crystal hydration for single crystals ${ }^{19,20}$. However, to maintain a controlled humidity environment for our hit-and-return (HARE)-chip setup including the liquid-applicationmethod for time-resolved crystallography (LAMA) ${ }^{21,22}$, required the development of a solution that could accommodate this larger experimental setup. To this end we have constructed a modular, portable environmental control box that encloses our previously described chip-setup including the LAMA droplet injector nozzle on a footprint of $118 \mathrm{~mm}$ x $283 \mathrm{~mm}\left(\right.$ Fig. 1, 2) ${ }^{15}$.

Humidity control is achieved by flowing dry air either directly into the box, or first passing through a water bath $\left(20-95^{\circ} \mathrm{C}\right)$, with the proportion of gas through each channel controlled by a toggling (ball) valve in a (PID-) feedback loop. The water-bath is connected to the environmental control box via a silicone hose, to which a heating belt is attached preventing (re)condensation. Humidity control is achieved by flowing dry air either directly into the box, or first passing through a water bath (20-95 ${ }^{\circ} \mathrm{C}$ ), with the proportion of gas through each channel controlled by a toggling ball valve in a PIDfeedback loop. The water-bath is connected to the environmental control box via a silicone hose, to which a heating belt is attached preventing condensation. The target value can be achieved with high accuracy, enabling humidity control in the single point scale, while on the other hand as well as controlled crystal dehydration if that is required.

In addition to humidity, temperature within the enclosure can be set anywhere within the range $\sim 7^{\circ} \mathrm{C}$ to above $80^{\circ} \mathrm{C}$. An aluminum air-stream reflector directs the stream of humid air around the chip. In order to enable effective control over this wide temperature range, the box uses two modular temperature control units (Fig. 2). Module 1 covers a temperature range from $\sim 7^{\circ} \mathrm{C}$ to $\sim 55^{\circ} \mathrm{C}$, while module 2 covers a temperature range from $\sim 50^{\circ} \mathrm{C}$ to $>80^{\circ} \mathrm{C}$. Rapid exchange of the modules is possible without tools, enabling switching between different temperature regimes within a few minutes. Module 1 is a watercooled Peltier-element that enables active cooling or heating of the interior of the box. To ensure the temperature is equilibrated across the box the module is equipped with fans. Cooling water and circuit control are fed in through the top side of the module. The heating element in module 2 is a power resistor network that disseminates sufficient heat to increase the interior temperature of the box to $>80^{\circ} \mathrm{C}$, while the relative humidity can be sustained at over $95 \%$. Temperature control is achieved by 
a PID controller that sets the current through the Peltier elements and resitor network, respectively, to maintaining the target temperature.

The base of the box is made from durable polyether ether ketone (PEEK). To drain condensation water, several cotton wicks are fixed around the bottom corners and connected to an active pumping system that quickly drains excess liquid from the box. The sides and the lid of the box are made of $6 \mathrm{~mm}$ thick acrylic glass, while the rear panel (X-ray side) is made of acrylic glass and polyoxymethylene (POM). As an X-ray entrance window, an $8 \mathrm{~mm}$ opening in the POM is covered with two layers of COC foil, about $1 \mathrm{~mm}$ apart. To enable easy replacement of the X-ray entraynce window, the COC-foil is placed on a magnetically mounted ring, that tightly seals the inside of the box.

While the right panel is solid, the left panel has a feedthrough for the humidity tube, and an access hatch through which HARE chips can be loaded onto the sample translation stage. The front panel (detector side) is an aluminum frame with a $190 \mathrm{~mm}$ opening. This is sealed with two X-ray transparent Mylar foils $(6 \mu \mathrm{m})$, as a an exit window for the diffracted beam. To reduce condensation on this window, the space between the Mylar-foils is continuously flushed with warm air. The lid of the box contains feedthroughs for the humidity- and temperature-sensors, as well as for the electropneumatic retractable, infrared (IR) backlight, the LAMA-nozzle lever, and an access port for heating module exchange.

The translation stage system implemented on T-REXX P14 EH2 is not humidity resistant and therefore has to be kept on the outside of the box. Hence, the translation stages are connected to the box via a flexible bellow, custom cut from two layers of commercial plastic wrap. On the inside, the bellow is sealed around the arm between the translation stages and the kinematic mount for the chip holder ${ }^{23,24}$. To reduce the heat capacity of the chip holder, and thus maintain faster temperature equilibration the previously described aluminum chip holder design was fabricated from PEEK, providing the same functionality at a lighter weight ${ }^{24}$.

The LAMA nozzle is attached via a kinematic mount to a retractable lever, that enables retraction of the nozzle from its injection position during chip exchange. To avoid the unnecessary opening of the box, which might lead to temperature and humidity fluctuations, the nozzle retracts into a parking position under the lid of the box. Fine LAMA nozzle alignment in the injector position is achieved via motorized translation stages (Thorlabs).

The whole box system is mounted on rails, residing on a stainless-steel baseplate that can be moved between "data collection" or "beam location" position, where the latter allows to use the X-ray scintillator built into the beam-shaping device (BSD; Arinax, Moirans France).

Operation of the serial crystallography environmental control enclosure is achieved via an external control unit where temperature and humidity parameters are electronically set (Fig. 3). Parameters needed to achieve certain conditions were calibrated and are listed in Table 1. 


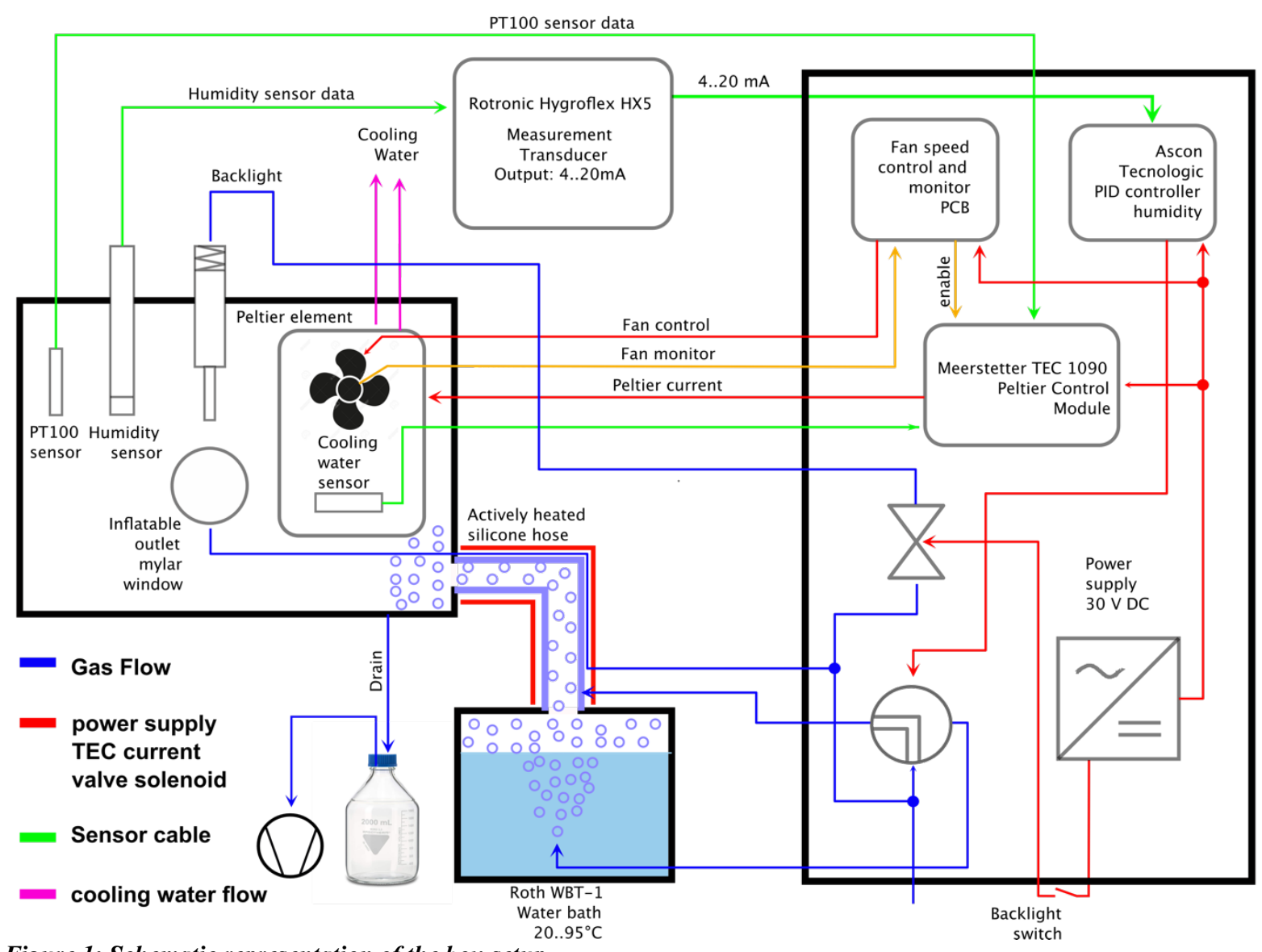

Figure 1: Schematic representation of the box-setup.

Displayed a schematic representation of the box-setup: gas flow is indicated by blue lines, power supply is red, while sensor cables are depicted in green, colling water is displayed in pink.. 
a)

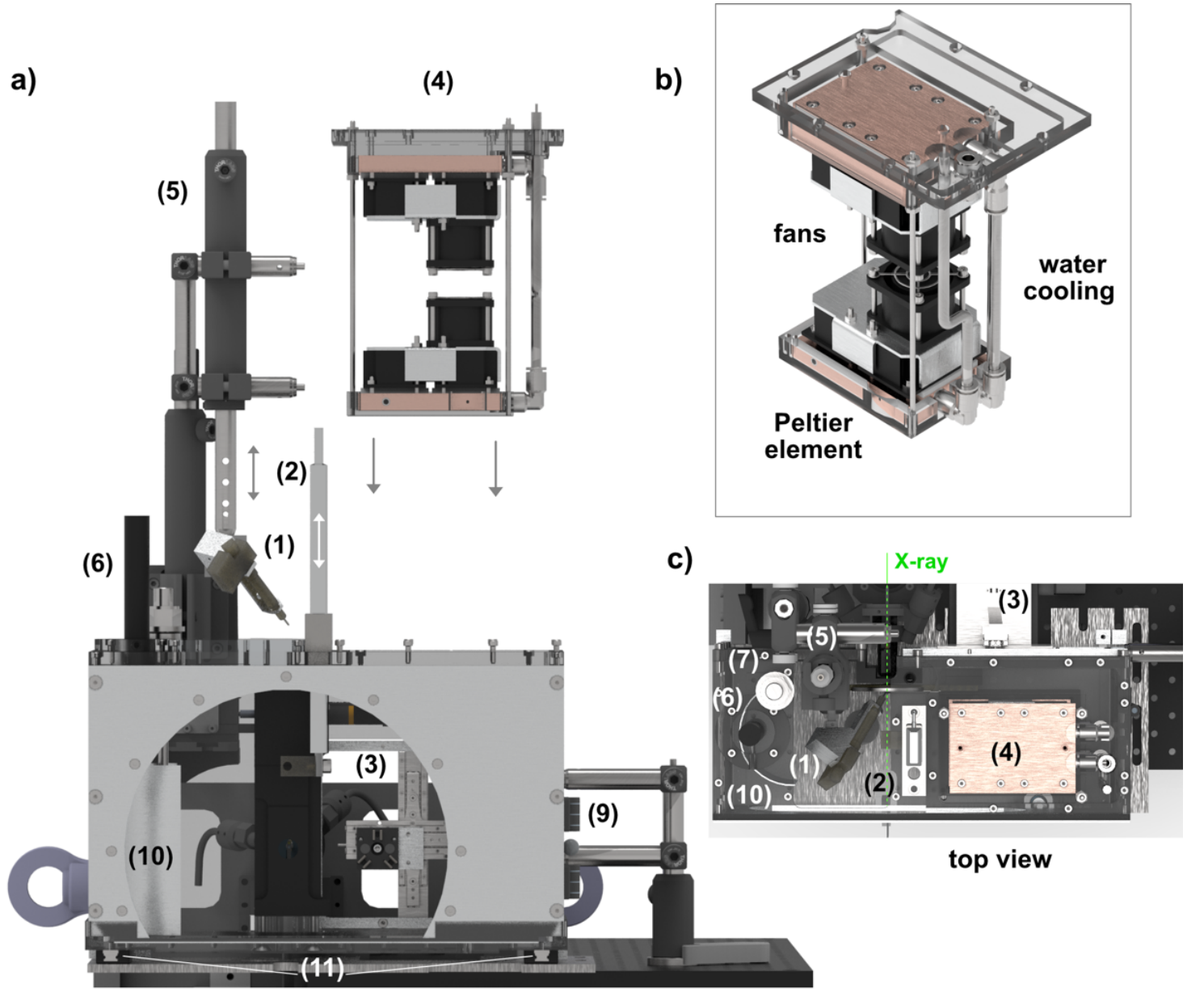

top view

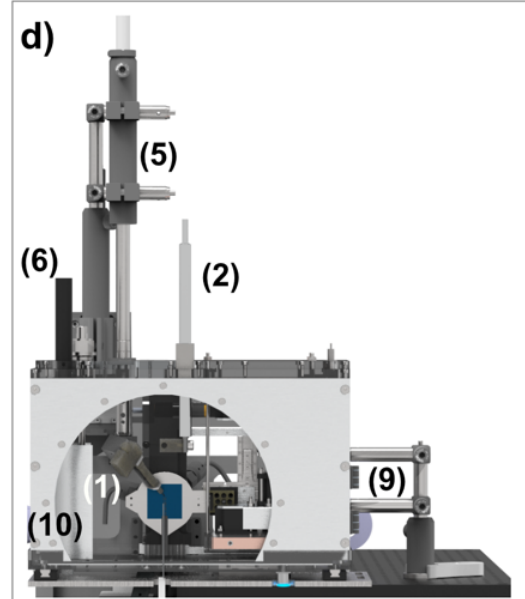

front

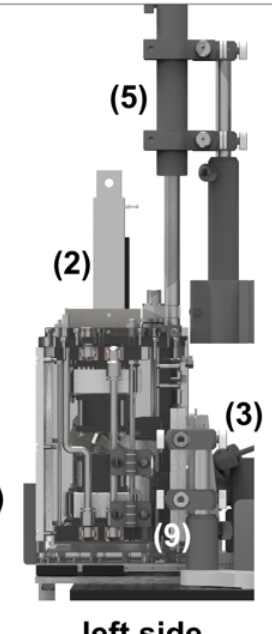

left side
(5)

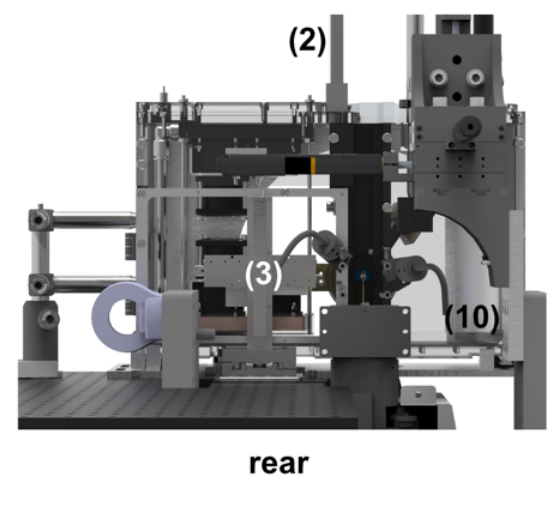

\section{(1): LAMA nozzle}

(4): Peltier module

(7): temperature sensor

(10): air stream reflector

(2): IR backlight

(5): LAMA guillotine

(8): beamstop

(11): retraction rails

(3): translation stages

(6): humidity sensor

(9): access hatch

Figure 2: The 'Serial Crystallography Environmental Control Enclosure'. a) overview of the environmental control box, with retracted LAMA nozzle and Peltier module. b) closeup of the Peltier module, c) top-view providing an overview of the arrangement inside the box, d) front-, side- and rear-view of the box. Note: for clarity not all technical elements of the box (e.g. tubing, electric connections etc.) or the beamline are shown or described in detail. Elements mentioned in the text are numbered and shown in the figure legend. 
bioRxiv preprint doi: https://doi.org/10.1101/2021.11.07.467596; this version posted November 8, 2021. The copyright holder for this preprint (which was not certified by peer review) is the author/funder. All rights reserved. No reuse allowed without permission.

a)

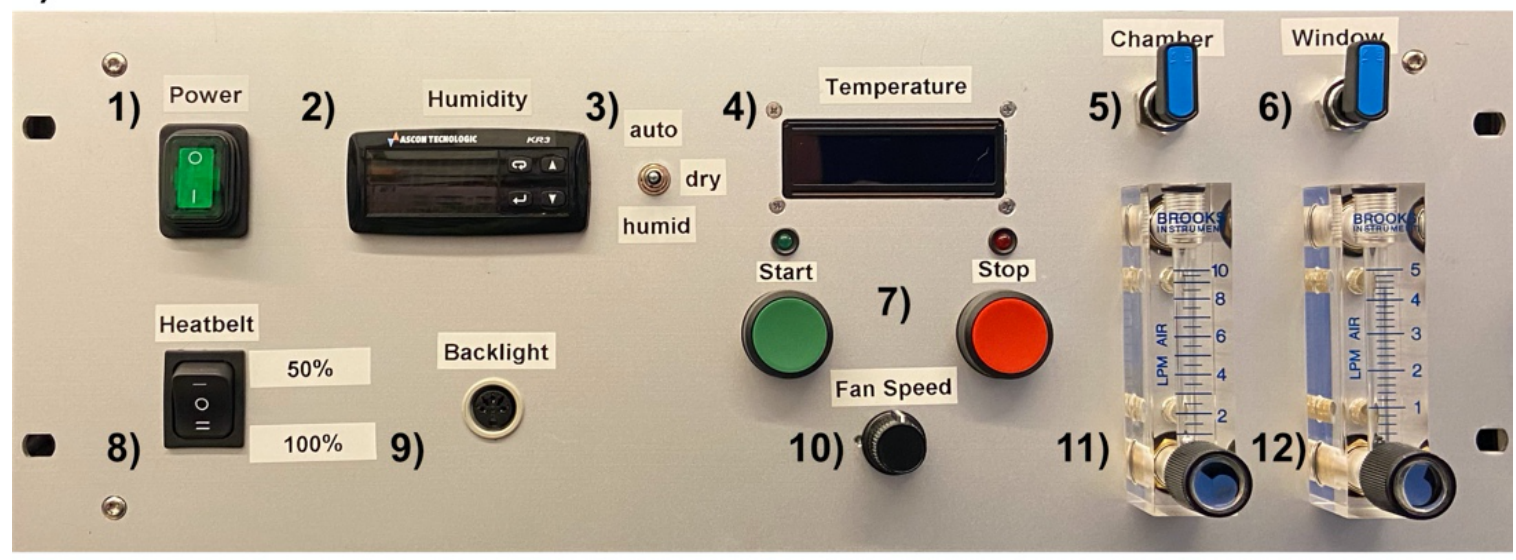

b)

front

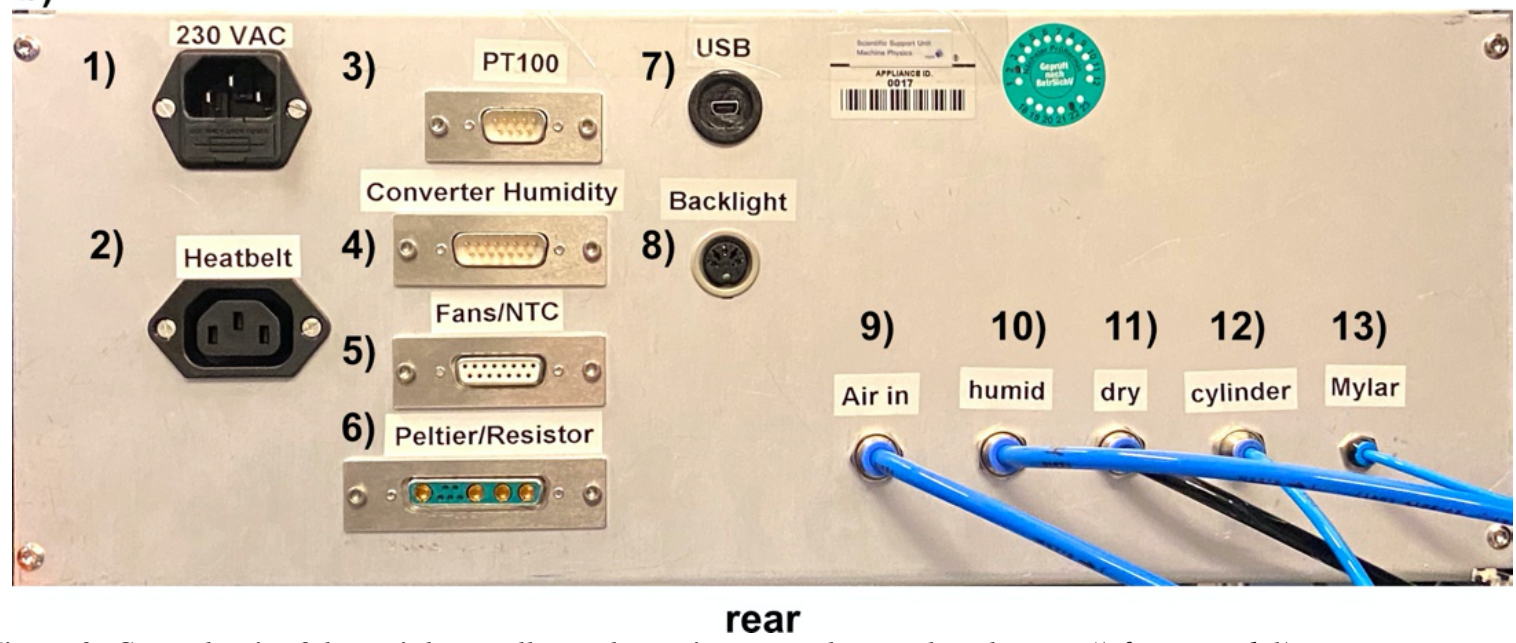

Figure 3: Control unit of the serial crystallography environmental control enclosure. A) front panel:1) main power switch; 2) humidity control / display; 3) air flow destination switch; 4) temperature display; 5) airflow on/off switch; 6) inflatable front-window flow on/off switch; 7) Temperature control start/stop button; 8) heat-belt switch; 9) socket for IR backlight switch; 10) fan-speed regulator; 11) air-flow valve; 12) front-window flow valve. b) rear panel: 1) main power inlet; 2) heat belt power outlet; 3) PT100 temperature sensor; 4) humidity sensor; 5) fan connection; 6) Peltier/resistor connection; 7) USB connection to PC; 8) backlight outlet; 9) pressurized air in; 10) air flow to water-bath; 11) dry air outlet; 12) backlight cylinder air outlet; 13) inflatable front-window air outlet 
Table 1: environmental control parameter settings

\begin{tabular}{|c|c|c|c|c|c|c|}
\hline $\begin{array}{c}\text { desired } \\
\text { temp } \\
{ }^{\circ} \mathrm{C}\end{array}$ & $\begin{array}{c}\text { flow } \\
\text { rate } \\
\mathrm{L} \text { min }^{-1}\end{array}$ & $\begin{array}{c}\text { desired } \\
\text { humidity } \\
\%\end{array}$ & $\begin{array}{c}\text { actual } \\
\text { humidity } \\
\%\end{array}$ & $\begin{array}{c}\text { water bath } \\
\text { temp } \\
{ }^{\circ} \mathbf{C}\end{array}$ & $\begin{array}{c}\text { heat belt } \\
\text { power } \\
\%\end{array}$ & $\begin{array}{c}\text { measure } \\
\text { curren } \\
\text { A }\end{array}$ \\
\hline 7.5 & 5 & 95 & 95 & 75 & 0 & -12.3 \\
\hline 15 & 5 & 95 & 95 & 75 & 50 & -2.1 \\
\hline 25 & 5 & 95 & 95 & 75 & 100 & 1.7 \\
\hline 35 & 4 & 95 & 95 & 85 & 100 & 3.5 \\
\hline 45 & 4 & 95 & 95 & 95 & 100 & 4.8 \\
\hline 55 & 4 & 95 & 95 & 95 & 100 & 6 \\
\hline
\end{tabular}

\begin{tabular}{ccccccc}
$\begin{array}{c}\text { Module } \mathbf{2} \\
\text { desired temp } \\
{ }^{\circ} \mathbf{C}\end{array}$ & $\begin{array}{c}\text { flow rate } \\
\text { L } \text { min }^{-1}\end{array}$ & $\begin{array}{c}\text { desired humidity } \\
\mathbf{\%}\end{array}$ & $\begin{array}{c}\text { actual humidity } \\
\mathbf{\%}\end{array}$ & $\begin{array}{c}\text { water bath temp } \\
{ }^{\circ} \mathbf{C}\end{array}$ & $\begin{array}{c}\text { heat belt power } \\
\text { \% }\end{array}$ & $\begin{array}{c}\text { current } \\
\text { A }\end{array}$ \\
\hline & & & & & \\
50 & 4 & 95 & 95 & 95 & 100 & 2.4 \\
55 & 4 & 95 & 95 & 95 & 100 & 2.9 \\
60 & 4 & 95 & 95 & 95 & 100 & 2.6 \\
65 & 4 & 95 & 95 & 95 & 100 & 2.9 \\
70 & 4 & 95 & 95 & 95 & 100 & 3.1 \\
75 & 4 & 95 & 95 & 95 & 100 & 4.3 \\
80 & 4 & 95 & 95 & 95 & 100 & 3.4
\end{tabular}

\section{Characterization of the environmental control}

To characterize how the environmental parameters can be controlled within the box, we recorded temperature and humidity changes as a function of time in $30 \mathrm{sec}$ intervals. The temperature was modified as a step function, with the humidity target set to $95 \%$. While the humidity rapidly equilibrates throughout the box, temperature gradients closer to the walls needs to be avoided. In addition to the overall temperature inside the box, we also monitored the temperature at two additional locations, directly on the surface of the backside of the HARE-chip and directly above the humidity sensor (Fig. 4). To assess how effectively different temperatures in the box can be achieved and maintained, we characterized the temperature increase from $7.5^{\circ} \mathrm{C}$ to $80^{\circ} \mathrm{C}$. The data show that for both temperature control modules the humidity values quickly reach the target values. Over a temperature window of almost $50{ }^{\circ} \mathrm{C}$ the humidity remains stable within $2.5 \%$ of the target value. Analysis of the deviation of the chip temperature from the box temperature shows that the chip temperature follows the box temperature with a median difference of $0.7^{\circ} \mathrm{C}$, over a temperature window of almost $50^{\circ} \mathrm{C}$. Temperature and humidity typically equilibrate across the box and the chip 10-15 minutes. 
bioRxiv preprint doi: https://doi.org/10.1101/2021.11.07.467596; this version posted November 8, 2021. The copyright holder for this

preprint (which was not certified by peer review) is the author/funder. All rights reserved. No reuse allowed without permission.

a)

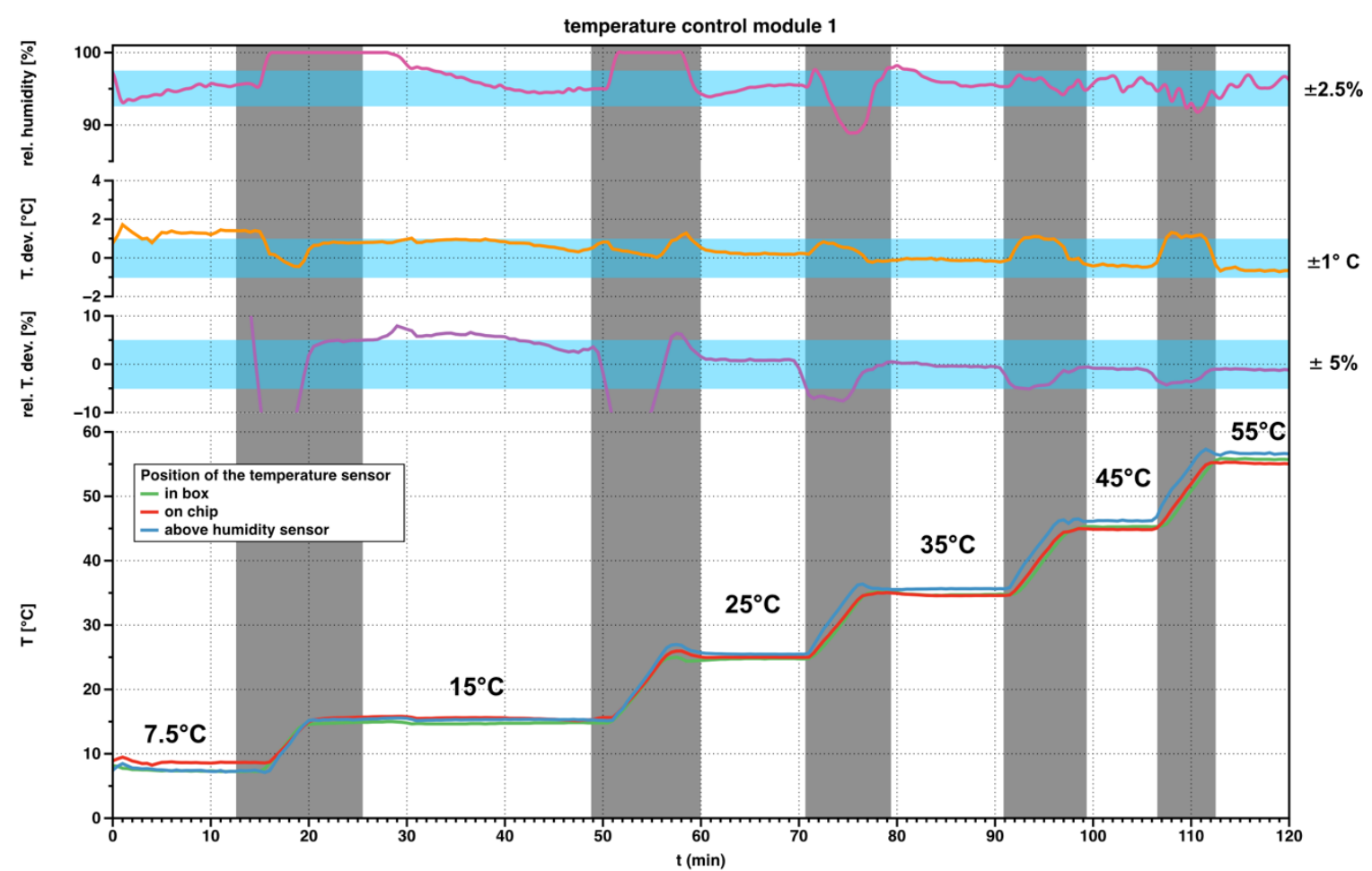

b)

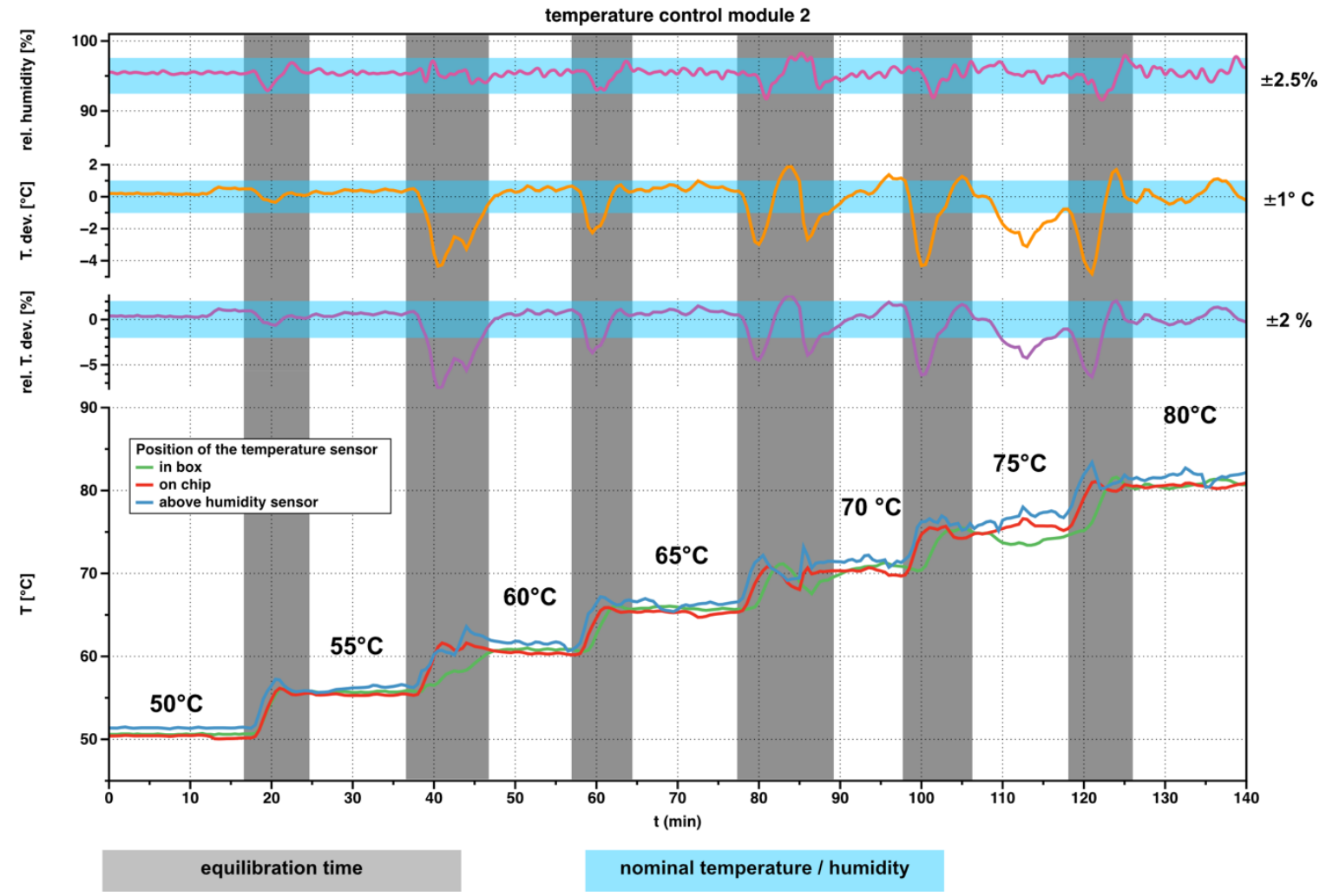

Figure 4: Characterization of the environmental control. a) module 1: $7.5^{\circ} \mathrm{C}-55^{\circ} \mathrm{C}$; b) module 2: $50-80^{\circ} \mathrm{C}$; The temperature was successively increased from 7.5 to $55^{\circ} \mathrm{C}$ and 50 to $80^{\circ} \mathrm{C}$ respectively. The temperature was controlled at three independent positions inside of the chamber: green in the box, blue directly above the humidity sensor, red directly on the chip. The target humidity was set to 95\%. The grey bars indicate the equilibration time, blue bars indicate the target window. 
We also examined how well the environmental target values can be maintained during X-ray datacollection. To this end we collected $\mathrm{X}$-ray diffraction data at $20^{\circ} \mathrm{C}, 40{ }^{\circ} \mathrm{C}, 55^{\circ} \mathrm{C}$ and $80{ }^{\circ} \mathrm{C}$, for $\sim 120$ minutes and recorded temperature and humidity values in $30 \mathrm{sec}$ intervals during this period (Table 2). Remarkably, during the data-collection the target humidity could be maintained within $\sim 1 \%$, while the temperature remained stable within $\sim 0.5^{\circ} \mathrm{C}$. Clear deviations from this behavior are only observed during chip-exchange, when the hatch of the box is opened and during the subsequent reequilibration time while the environment restabilises. Reequilibration of the environmental parameters could be achieved within $\sim 10-15$ minutes, depending on the manual chip-exchange times.

In conclusion, these data show that after an equilibration time of $\sim 10-15$ minutes the environment in the control box has reached its target value, and that this can be maintained throughout extended periods of time, well beyond the typical data collection time of a chip (30 minutes). This enables collection of serial X-ray diffraction data at a variety of different temperatures with high accuracy and precision.

Table 2:Environmental parameters during X-ray diffraction data collection.

*values are derived from a long-term, $(10 \mathrm{~h})$ data-collection

\begin{tabular}{cccccc}
\hline $\begin{array}{c}\text { nominal } \\
\text { temperature }\left({ }^{\circ} \mathrm{C}\right)\end{array}$ & $\begin{array}{c}\text { nominal rel. } \\
\text { humidity (\%) }\end{array}$ & $\begin{array}{c}\text { measure rel. } \\
\text { humidity }(\%)\end{array}$ & rmsd (\%) & $\begin{array}{c}\text { measured } \\
\text { temperature } \\
\left({ }^{\circ} \mathrm{C}\right)\end{array}$ & $\operatorname{rmsd}\left({ }^{\circ} \mathrm{C}\right)$ \\
\hline 20 & 95 & 95.4 & 0.5 & 19.8 & 0.2 \\
40 & 95 & 95.5 & 0.9 & 40.3 & 0.3 \\
55 & 95 & 95.5 & 0.7 & 55.3 & 0.7 \\
80 & 95 & 95.2 & 0.7 & 80.1 & 0.3 \\
$20^{*}$ & $95 *$ & $95.2^{*}$ & $0.7^{*}$ & $19.8^{*}$ & $0.2^{*}$ \\
\hline
\end{tabular}

\section{Humidity dependent unit-cell modulation}

Adjusting the relative humidity either prior to or during data-collection can improve several aspects of data-quality (resolution, mosaicity and anisotropy) ${ }^{25-33}$. To estimate the effect of the environmental humidity on diffraction data quality we monitored the unit-cell size of XI as a function of decreasing humidity. We started data-collection at a relative humidity of $95 \%$ and reduced the humidity in discrete steps of 5\% per compartment row on the chip (Fig. 5 ). With decreasing humidity the crystals do not simply cease to diffract but undergo a change in unit-cell size. While at or above a relative humidity of 95\% most diffraction patterns could be indexed with a large unit-cell $(\mathrm{a}=94.2 \AA, \mathrm{b}=99.3 \AA, \mathrm{c}=103.1$ $\left.\AA ; \alpha, \beta, \gamma=90.0^{\circ}\right)$ the proportion rapidly changed to a smaller unit-cell $(\mathrm{a}=94.6 \AA, \mathrm{b}=99.4 \AA, \mathrm{c}=$ $87.5 \AA ; \alpha, \beta, \gamma=90.0^{\circ}$ ) as the relative humidity dropped from $90 \%$ to $75 \%$. If the humidity is reduced even further the micro-crystals cease to diffract, presumably due to complete dehydration. This emphasizes the sensitivity of protein-microcrystals to environmental humidity, which must be precisely controlled to maintain their diffraction properties. On the other hand, this also opens the opportunity for crystals with large unit-cells to be specifically dehydrated to modulate their diffraction properties. 
The response of protein crystals hydration to their environment has long been $\mathrm{known}^{34}$ and chemical dehydration devices ${ }^{35-38}$ as well as dedicated dehumidification devices have successfully been used for this purpose on single, loop-mounted crystals ${ }^{27-29}$. With this envirornmental control box these postcrystallization optimization protocols are now open to serial-crystallography.

a)

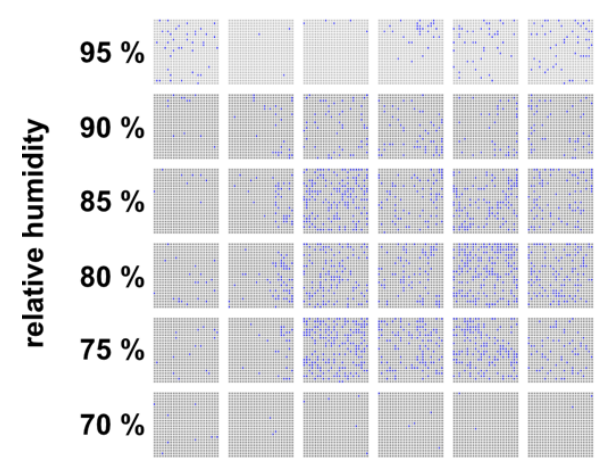

unit-cell parameters: b)

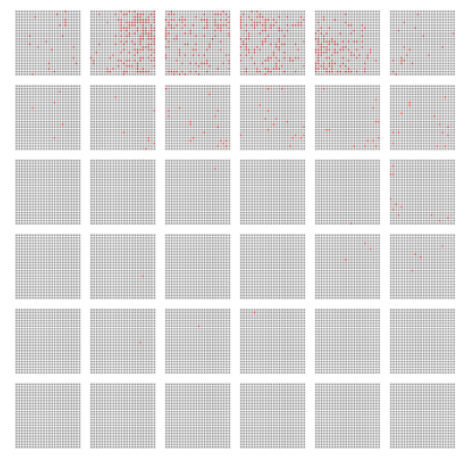

c)

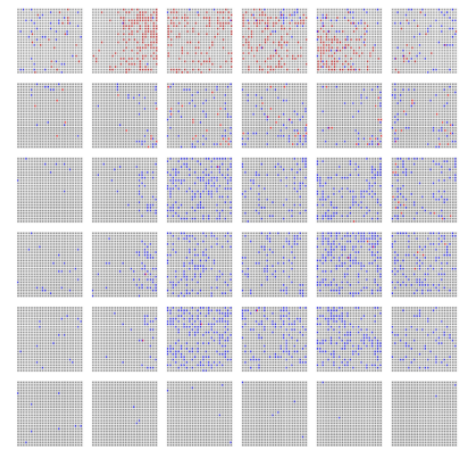

high-humidity: a,b,c = 94.2 $\AA, 99.3 \AA, 103.1 \AA ; \alpha, \beta, \gamma=90.0^{\circ}$

low-humidity: a,b,c = 94.6 $\AA, 99.4 \AA, 87.5 \AA ; \alpha, \beta, \gamma=90.0^{\circ}$

Figure 5: Humidity dependent unit-cell modulation displayed in a hit map. The HARE-chips consist of 6x6 compartments, divided into $24 \times 24$ features. Each feature is indicated by a small grey square; a blue-square indicates a diffraction pattern in the low humidity unit cell, a red square a diffraction pattern in the larger high-humidity unit-cell. Humidity has been reduced by $5 \%$ for each row of compartments. a) low-humidity diffraction patterns b) high-humidity diffraction patterns c) overlay of low- and high-humidity diffraction pattern hits.

\section{Multi-temperature structural analysis of xylose isomerase}

Exploiting the potential of this environment control box in a first proof-of-principle experiment, we have determined the structure of the hyperthermophile enzyme XI at six different temperatures: at $10^{\circ}$ $\mathrm{C}, 20^{\circ} \mathrm{C}, 30^{\circ} \mathrm{C}, 40^{\circ} \mathrm{C} 50^{\circ} \mathrm{C}$ and $60^{\circ} \mathrm{C}$, respectively. In general, all datasets could be processed to a resolution of $2 \AA$ or better and display reasonable data-statistics (Table 3). In particular, the diffraction data do not indicate any obvious influence of the temperature on the diffraction properties.

All refined structures superimpose with a C-alpha r.m.s.d. of $\sim 0.1 \AA$ to the $20^{\circ} \mathrm{C}$ structure. With increasing temperature, the overall B-factors show a monotonically-increasing trend. However, while the B-factors of core residues including the active site remain moderate and relatively constant, the solvent exposed interface and the substrate entry cleft show increased B-factors with increasing temperature (Table 3; Fig. 6).

The high degree of conformational homogeneity is also reflected in the active site (Fig. 7). Here all residues superimpose almost perfectly, with a minimal amount of heterogeneity visible in Lys289, which adopts two alternate conformations and shows slightly increased B-factors as the temperature is increased. In addition to the amino acid side chains, the metal sites M1 and M2 remain in identical positions. The main differences that are observed lie in the position of the water molecules, in particular 
those further away from the metal sites. These features emphasize the evolutionary adaptation of xylose isomerase to withstand higher temperatures and reflect the general structural rigidity of the enzyme.

Table 3: Data collection and refinement statistics of the apo data. Values in the highest resolution shell are shown in parenthesis.

\begin{tabular}{|c|c|c|c|c|c|c|}
\hline Temperature $\left({ }^{\circ} \mathrm{C}\right)$ & 10 & 20 & 30 & 40 & 50 & 60 \\
\hline relative humidity $(\%)$ & $98 \%$ & $95 \%$ & $98 \%$ & $98 \%$ & $98 \%$ & $98 \%$ \\
\hline Ligand & \multicolumn{6}{|c|}{ apo } \\
\hline Space group & \multicolumn{6}{|c|}{$\mathrm{I} 222$} \\
\hline $\mathrm{a}, \mathrm{b}, \mathrm{c}(\AA)$ & \multicolumn{6}{|c|}{$94.2,103.1,99.3$} \\
\hline$\alpha, \beta, \gamma\left(^{\circ}\right)$ & \multicolumn{6}{|c|}{$90.0,90.0,90.0$} \\
\hline number of indexed images & 7346 & 11115 & 8019 & 17004 & 5128 & 10007 \\
\hline Resolution $(\AA)$ & $\begin{array}{c}71.5-1.9 \\
(1.97-1.90)\end{array}$ & $\begin{array}{c}71.4-1.8 \\
(1.86-1.80)\end{array}$ & $\begin{array}{c}71.4-1.9 \\
(1.97-1.90)\end{array}$ & $\begin{array}{c}71.4-1.8 \\
(1.86-1.80)\end{array}$ & $\begin{array}{c}71.4-2.0 \\
(2.07-2.00)\end{array}$ & $\begin{array}{c}71.4-1.9 \\
(1.97-1.90)\end{array}$ \\
\hline $\mathrm{CC} *(\%)$ & $93.09(77.93)$ & $96.3(73.06)$ & $\begin{array}{c}94.43 \\
(79.31)\end{array}$ & $\begin{array}{c}97.90 \\
(70.35)\end{array}$ & $\begin{array}{c}91.38 \\
(70.44)\end{array}$ & $96.70(70.63)$ \\
\hline $\mathrm{R}_{\text {split }}(\%)$ & $43.79(89.24)$ & $\begin{array}{c}33.85 \\
(113.4)\end{array}$ & $\begin{array}{c}40.54 \\
(89.36)\end{array}$ & $\begin{array}{c}28.66 \\
(129.23)\end{array}$ & $\begin{array}{c}50.82 \\
(111.71)\end{array}$ & $\begin{array}{c}32.79 \\
(124.08)\end{array}$ \\
\hline$<\mathrm{I} / \sigma(\mathrm{I})>(\mathrm{SNR})$ & $2.06(1.11)$ & $2.51(0.90)$ & $2.18(1.11)$ & $2.74(0.82)$ & $1.83(0.90)$ & $2.42(0.81)$ \\
\hline Mutliplicity & $69.5(47.7)$ & $\begin{array}{c}424.9 \\
(289.9)\end{array}$ & $\begin{array}{c}154.0 \\
(105.7)\end{array}$ & $\begin{array}{l}1169.6 \\
(801.8)\end{array}$ & $88.8(61.1)$ & $69.9(47.8)$ \\
\hline Completeness $(\%)$ & \multicolumn{6}{|c|}{$100.00(100.00)$} \\
\hline Resolution range for refinement $(\AA)$ & $71.49-1.90$ & $71.49-1.80$ & $71.49-1.90$ & $71.49-1.80$ & $71.49-2.00$ & $71.49-1.90$ \\
\hline No. Reflections & 38388 & 45053 & 38388 & 41536 & 32995 & 38388 \\
\hline $\mathrm{R}_{\text {work }}(\%)$ & 20.54 & 17.67 & 18.93 & 16.91 & 21.04 & 18.32 \\
\hline $\mathrm{R}_{\text {free }}(\%)$ & 25.49 & 21.08 & 23.21 & 20.67 & 25.43 & 23.03 \\
\hline \multicolumn{7}{|l|}{ Mean B-factor $\left(A^{2}\right)$} \\
\hline overall & 23.76 & 24.82 & 24.44 & 28.44 & 28.17 & 34.57 \\
\hline protein & 22.42 & 23.55 & 23.33 & 27.53 & 27.18 & 33.31 \\
\hline water & 36.37 & 36.37 & 35.54 & 38.87 & 37.46 & 48.31 \\
\hline other & 19.82 & 20.5 & 18.1 & 20.53 & 21.3 & 21.26 \\
\hline \multicolumn{7}{|l|}{ Rms Deviations } \\
\hline Bond Length $(\AA)$ & 0.006 & 0.009 & 0.01 & 0.008 & 0.003 & 0.012 \\
\hline Bond Angles $\left({ }^{\circ}\right)$ & 0.848 & 1.012 & 1.061 & 0.927 & 0.545 & 1.154 \\
\hline \multicolumn{7}{|l|}{ Ramachandran } \\
\hline Favored (\%) & 97.14 & 97.14 & 97.4 & 97.14 & 96.87 & 96.59 \\
\hline Allowed (\%) & 2.6 & 2.6 & 2.34 & 2.6 & 2.87 & 3.15 \\
\hline Outliers (\%) & 0.26 & 0.26 & 0.26 & 0.26 & 0.26 & 0.26 \\
\hline
\end{tabular}


a)
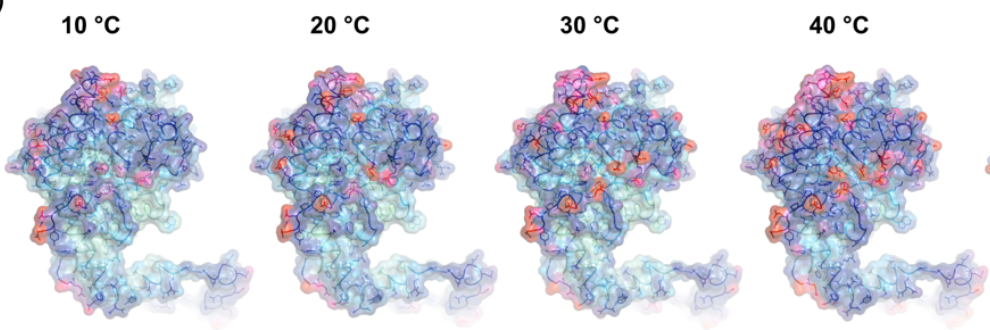

$50{ }^{\circ} \mathrm{C}$

$60{ }^{\circ} \mathrm{C}$

B-factor

b)

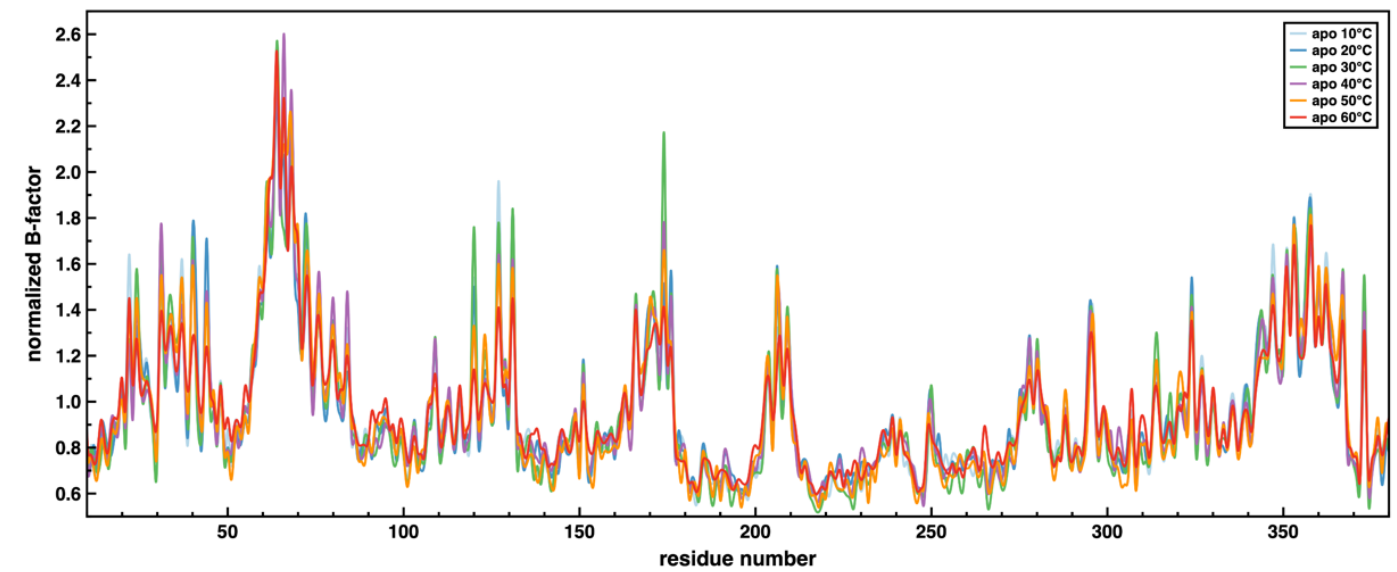

Figure 6: B-factor distribution as a function of temperature. a) A semi-transparent surface representation of the XI monomers, collected at 6 different temperatures. Coloring is according to the B-factor spectrum from $5 A^{2}$ to $50 \AA^{2}$ shown at the bottom. b) A plot of the normalized B-factors per residue for each structure. Ten residues on the N-terminus and eight residues at the C-terminus have been omitted for better visualization. Clearly no part of the apo structure is particularly sensitive to an increase in temperature.

a)

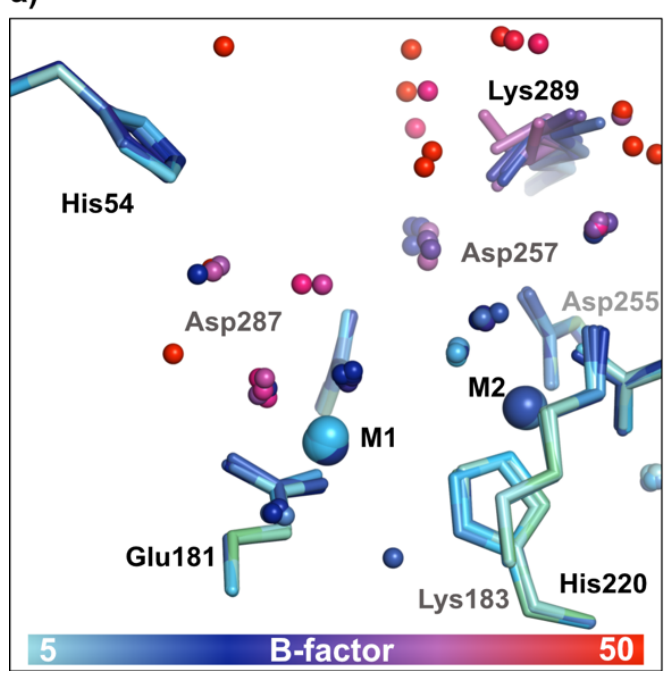

b)

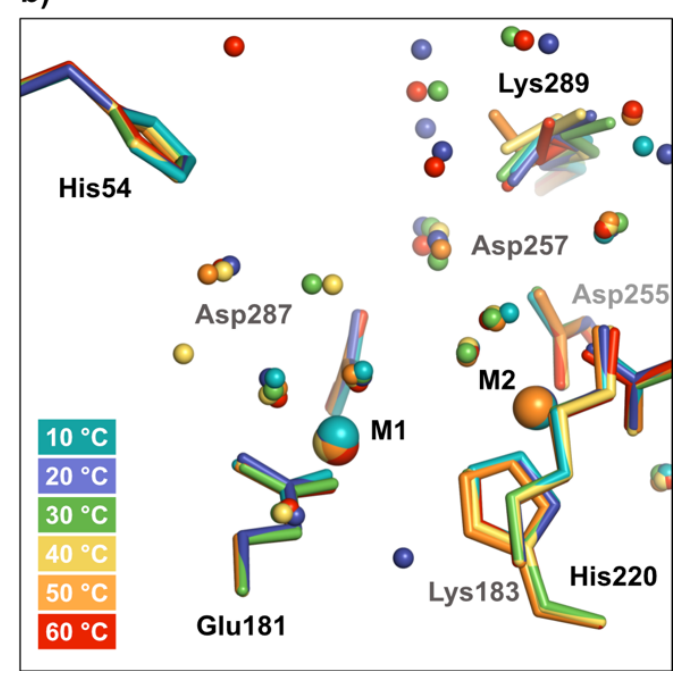

Figure 7:Active site of apo XI at temperatures from $10^{\circ} \mathrm{C}$ to $60^{\circ} \mathrm{C}$. a) The active site of XI colored according to B-factor as indicated on the scale-bar. b) The active site residues of XI colored according to temperature, as indicated in the legend. 


\section{D-SSX reveals temperature dependent electron density changes}

To assess the effect of temperature on the catalytic reaction of XI, we triggered the reaction by adding the substrate glucose (alpha-D-glucose) using LAMA ${ }^{39}$ and monitored its turnover at a constant timedelay of 60 seconds after reaction initiation at $20^{\circ} \mathrm{C}, 40^{\circ} \mathrm{C}, 45{ }^{\circ} \mathrm{C}$ and $50^{\circ} \mathrm{C}$. Like the apo-data, the 5D datasets show good X-ray diffraction data-statistics (Table 4). A minimally lower resolution can be observed for the $50^{\circ} \mathrm{C}$ dataset, but this is likely due to the lower number of images in this dataset rather than the increased temperature.

Table 4: Data collection and refinement statistics of the 60 sec data. Values in the highest resolution shell are shown in parenthesis.

\begin{tabular}{|c|c|c|c|c|}
\hline Time-Delay (s) & 60 & 60 & 60 & 60 \\
\hline Temperature $\left({ }^{\circ} \mathrm{C}\right)$ & 20 & 40 & 45 & 50 \\
\hline relative humidity (\%) & $99.0 \%$ & $98.5 \%$ & $95.0 \%$ & $98.5 \%$ \\
\hline Ligand & \multicolumn{4}{|c|}{ glucose } \\
\hline Space group & \multicolumn{4}{|c|}{$\mathrm{I} 222$} \\
\hline $\mathrm{a}, \mathrm{b}, \mathrm{c}(\AA)$ & \multicolumn{4}{|c|}{$94.20,103.05,99.25$} \\
\hline$\alpha, \beta, \gamma\left(^{\circ}\right)$ & \multicolumn{4}{|c|}{$90.0,90.0,90.0$} \\
\hline number of images & 9346 & 12349 & 9389 & 5224 \\
\hline Resolution ( $\AA$ ) & $71.43-1.7(1.76-1.70)$ & $71.43-1.7(1.76-1.70)$ & $71.43-1.7(1.86-1.80)$ & $71.43-1.90(1.97-1.90)$ \\
\hline CC* $(\%)$ & $94.63(63.38)$ & $95.45(68.81)$ & $95.39(68.99)$ & $92.10(73.08)$ \\
\hline $\mathrm{R}_{\text {split }}(\%)$ & $38.94(141.80)$ & $34.99(126.20)$ & $36.90(117.50)$ & $45.59(102.08)$ \\
\hline$<\mathrm{I} / \sigma(\mathrm{I})>(\mathrm{SNR})$ & $2.27(0.69)$ & $2.65(0.80)$ & $2.36(0.86)$ & $2.11(1.01)$ \\
\hline Mutliplicity & $156.6(93.8)$ & $109.1(65.6)$ & $125.2(85.4)$ & $94.7(64.9)$ \\
\hline Completeness (\%) & \multicolumn{4}{|c|}{$100.00(100.00)$} \\
\hline $\begin{array}{l}\text { Resolution range for } \\
\text { refinement }(\AA)\end{array}$ & $71.49-1.70$ & $71.49-1.70$ & $71.49-1.80$ & $71.49-1.90$ \\
\hline No. Reflections & 32995 & 53373 & 45053 & 38388 \\
\hline $\mathrm{R}_{\mathrm{work}}(\%)$ & 18.38 & 18.05 & 17.68 & 19.48 \\
\hline $\mathrm{R}_{\text {free }}(\%)$ & 21.91 & 21.84 & 21.37 & 24.26 \\
\hline \multicolumn{5}{|l|}{ Mean B-factor $\left(A^{2}\right)$} \\
\hline overall & 20.03 & 25.21 & 25.69 & 24.73 \\
\hline protein & 19.12 & 23.87 & 24.82 & 23.81 \\
\hline water & 29.5 & 38.13 & 35.6 & 34.55 \\
\hline other & 20.84 & 25.7 & 23.56 & 21.14 \\
\hline \multicolumn{5}{|l|}{ Rms Deviations } \\
\hline Bond Length $(\AA)$ & 0.002 & 0.008 & 0.011 & 0.007 \\
\hline Bond Angles $\left({ }^{\circ}\right)$ & 0.481 & 0.953 & 1.102 & 0.851 \\
\hline \multicolumn{5}{|l|}{ Ramachandran } \\
\hline Favored (\%) & 97.14 & 96.35 & 96.61 & 96.88 \\
\hline Allowed (\%) & 2.6 & 3.39 & 3.12 & 2.86 \\
\hline Outliers (\%) & 0.26 & 0.26 & 0.26 & 0.26 \\
\hline
\end{tabular}

Clearly, the $20^{\circ} \mathrm{C}$ structure is in complex with a closed-ring glucose molecule, indicating that a ring opening reaction had not yet begun. The respective substrate complex structure at $20^{\circ} \mathrm{C}$ can be superimposed with an r.m.s.d. of $0.1 \AA$ to previously reported substrate complexes at room temperature (PDB-ID: 3KCL) ${ }^{40}$ (Fig. 8). 
From temperatures above $40^{\circ} \mathrm{C}$ the electron density in the active site clearly changes from that of the lower temperature data and can no longer be explained by a closed ring substrate molecule alone. Thus this electron density can be interpreted best as a mixture between several different states comprising the closed ring glucose and an open-ring intermediate, and presumably also the apo state.
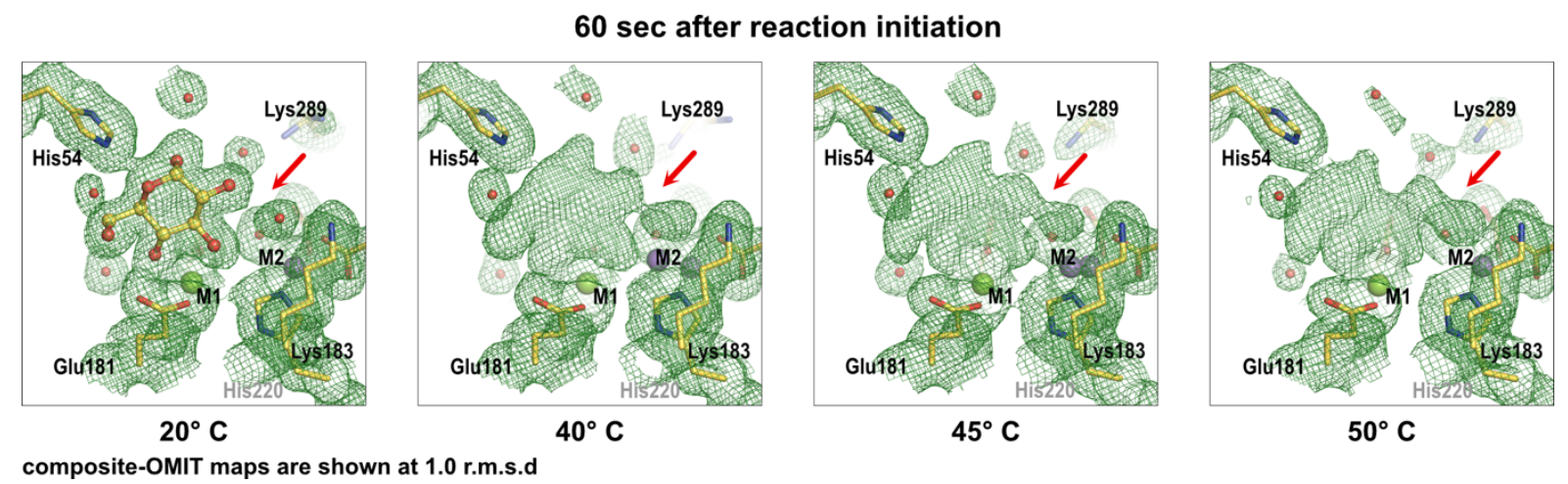

composite-OMIT maps are shown at 1.0 r.m.s.d

Figure 5: 5D-SSX reveals temperature dependent electron density changes. Xylose isomerase active site, 60 sec after reaction initiation at various temperatures. Composite-OMIT maps are shown around the active site at an r.m.s.d. of 1.0. Clearly, with increasing temperature the electron density changes (red arrow) and can no longer be interpreted by a single state alone, and multiple, overlapping states have to be modelled.

\section{Discussion}

Environmental control has consistently been a key aspect of macromolecular crystallography, as fragile protein crystals are sensitive to dehydration and physical stress. Open- and closed boundary environmental control solutions have been developed since the advent of structural biology. In the simplest instances, closed boundary devices include glass-capillaries, which retain protein crystals and typically a drop of mother liquor to sustain a humid atmosphere during data collection ${ }^{20}$. More modern variations of this classic solution are the many fixed-target serial crystallography environments, which protect protein microcrystals against evaporation by some form of X-ray transparent window material ${ }^{41}$. For single crystal experiments a variety of solutions, sometimes for advanced parameter control, such as humidity, temperature, and electric fields have also been developed over the years ${ }^{42-44}$. With the onset of cryo-crystallography, larger boxes were developed, which sometimes enclosed the stream of cryogenic gas in a dry atmosphere to prevent ice-formation during data-collection ${ }^{45}$. However, for single-crystal experiments the majority of environmental control solutions fall into the open-boundary category, such as placing the crystal in an vapor stream with controlled humidity ${ }^{27,43,46-49}$. Historically, the water content of protein crystals was controlled by post-crystallization treatments via chemical dehydration prior to crystal freezing ${ }^{34,36}$. However, controlling the humidity around the mounted crystals enables the convenient identification of the optimal conditions for a particular sample during an X-ray diffraction experiment ${ }^{27,43,46-49}$. Similar to humidity control, many beamlines are also equipped with a temperature control solution via a gas-stream that is directed at the sample, often encompassing wide temperature windows. Interestingly, however, a combined temperature-humidity 
control is rarely found. Such a situation mandates the use of e.g., glass capillaries to maintain the crystals in a humid environment, which complicates time-resolved applications that are based on insitu mixing. Historically, flow-cells were developed for time-resolved applications that allowed for insitu mixing experiments with single-crystals and for trapping reaction intermediates on comparably slow time-scales ${ }^{50-52}$. However, to the best of our knowledge these were not applied to multitemperature experiments. That is, so far the only other multi-temperature time-resolved crystallographic experiment was limited to PYP, a well-studied reversible system that is triggered via photoexcitation ${ }^{13,14}$.

Serial crystallography experiments can also be conducted in controlled, closed-boundary environments as demonstrated by the drop-on-demand device, which permits humidity control and for fully anaerobic experiments via the exchange of the surrounding atmosphere ${ }^{53}$. However, with current sample delivery devices no temperature modulation has been achieved for serial crystallography experiments. In this regard, our environmental control box charts a new area, enabling enzymatic reaction characterization that comprises the full spectrum of physiological temperatures from psychrophilic to (hyper)thermophile organisms. For the many irreversible mesophilic systems, we can now modulate enzyme kinetics through temperature variation, thereby accelerating or decelerating enzyme turnover and allowing for a more in-depth characterization of key enzymatic mechanisms. These can now be addressed at true physiological temperatures, enabling simultaneous correlation of mechanistic and thermodynamic aspects of protein function. Our solution combines environmental control with the advantages of serial crystallography in limiting radiation damage, as well as versatile delay-times provided by the HARE approach and the simplicity of reaction initiation of the LAMA-method ${ }^{15,22}$. The observed glucose structure demonstrated in this study corroborates previous observations. The clear changes in elecgtron density demonstrates a progression towards a 5-membered, closed-ring fructose product complex ${ }^{40,54,55}$. However, the multiple overlapping states make an unambiguous interpretation of the electron density difficult, which mandates the use of more complex modelling and analysis protocols in future experiments ${ }^{56,57}$. However, by increasing the temperature, different catalytic states, that is closed and likelyopen-chain intermediates can be captured at the same delay time, indicating an increase in the catalytic activity of xylose isomerase. Ergo, the modulation of the environmental temperature enables direct modulation of enzyme kinetics during a time-resolved X-ray diffraction experiment. Conducting similar experiments on other systems will allow us to understand how proteins exchange energy with their environment and how this is related to conformational dynamics and turnover. As described in the seminal paper by Schmidt et al., these multi-dimensional experiments will also permit determining experimental free-energy landscapes of proteins in action and thereby the elucidation of unique catalytic pathways ${ }^{13,58}$. These experiments should fertilize the cross pollination different aspects of biophysical chemistry. 


\section{Material and Methods}

\section{Sample preparation}

Crystals of Streptomyces rubiginosus Xylose Isomerase (XI) were obtained from Hampton Research (HR7-102) and stored at room temperature for several years. For this experiment the crystals were prepared as described previously ${ }^{15}$ : commercial crystals were re-dissolved in water and concentrated to $80 \mathrm{mg} / \mathrm{ml}$ in xylose-isomerase buffer (10 mM Hepes/ $\mathrm{NaOH} \mathrm{pH}$ 7.5). This protein solution was rediluted and concentrated again for 9 consecutive times to remove any remaining Tris/ $\mathrm{HCl}$ from the storage buffer. Subsequently microcrystals were obtained by vacuum induced crystallization, as described previously by Martin et al. ${ }^{59}$, in XI crystallization buffer (35\% (w/v) PEG3350, $200 \mathrm{mM}$ lithium sulfate and $10 \mathrm{mM}$ Hepes/ $\mathrm{NaOH}, \mathrm{pH}$ 7.5). For a typical chip sufficient microcrystal were prepared from $25 \mu \mathrm{L}$ protein solution $(80 \mathrm{mg} / \mathrm{ml}$ for xylose isomerase) combined with $25 \mu \mathrm{L}$ crystallization buffer. For droplet injection $1 \mathrm{M}$ glucose solution was prepared in $\mathrm{ddH}_{2} \mathrm{O}$ prior to data collection and stored at room temperature.

\section{Data processing and structure determination}

Diffraction data were processed using the CrystFEL package ${ }^{60}$. Structures were solved by molecular replacement using PHASER with our previously determined XI structure as a search model with one molecule in the asymmetric unit (PDB-ID: 6RNF) ${ }^{61}$. Structures were refined by iterative cycles in phenix.refine and manual model building of additional and disordered residues in COOT0.8 ${ }^{62-64}$. POLDER-OMIT maps were generated using the PHENIX package ${ }^{65}$. Molecular images were generated in $\mathrm{PyMOL}^{66}$.

\section{Experimental setup and data collection}

Diffraction data were collected at endstation P14-2 (T-REXX) at EMBL Hamburg on an Eiger 4M detector (Dectris, Baden-Daettwil, Switzerland) and a micro-focussed beam of $7 \times 10 \mu \mathrm{m}$. Time delays for time-resolve data collection were generated via the HARE method, reaction initiation was achieved via in-situ droplet injection via the LAMA method as previously described in detail ${ }^{15,22}$. Data-collection was conducted as previously described ${ }^{67}$ within the environmental control box mounted on the TREXX endstation. Briefly: chip-mounted microcrystals mounted in a HARE-chip solid target containing $\sim 20,000$ wells were moved through the X-ray beam using a 3-axis piezo translation stage (SmarAct, Oldenburg, Germany) ${ }^{21}$ ). As a broad guideline approximately 5000 still diffraction patterns were recorded per time-point as previously determined ${ }^{68}$, the droplet deposition into each well-defined the start of the reaction.

\section{Data interpretation}

Normalized B-factors were determined via the structure comparison tool of the phenix software suite ${ }^{72}$. 


\section{Acknowledgements}

All multi temperature SSX data were collected at beamline P14.2 (T-REXX) operated by EMBL Hamburg at the PETRA-III storage ring (DESY, Hamburg, Germany). We would like to thank our colleagues T.R. Schneider, G. Bourenkov and A.R. Pearson for their continuous support, helpful discussions and critical reading of the manuscript.

Funding: Construction of T-REXX was funded by the BMBF (Verbund Forschungsprojekt 05K16GU1). T-REXX beamtime was awarded as part of the EMBL BAG MX-660. The authors gratefully acknowledge the support provided by the Max Planck Society and the Cluster of Excellence 'The Hamburg Centre for Ultrafast Imaging' of the Deutsche Forschungsgemeinschaft (DFG) - EXC 1074 - project ID 194651731 and the Joachim Herz foundation (Biomedical physics of infection) (E.S.) and from the Joachim Herz Stiftung add-on fellowship (P.M.). Additional funding was provided by the DFG via grant No. 451079909 to PM and via grant No. 458246365 to ES.

\section{Author Contributions:}

P.M. and E.C.S. designed the experiments; E.C.S. and P.M. performed the experiments with support from D.v.S. and F.T.; P.M. prepared the protein crystals; E.C.S., P.M., J.P.L. and F.T. designed and built the environmental control box; D.v.S, E.C.S. and P.M. processed and analyzed the diffraction data; P.M. and E.C.S. wrote the manuscript; All authors discussed and corrected the manuscript.

\section{Competing Financial Interests Statement:}

The authors declare no competing financial interests. 


\section{References}

1. Deamer, D. \& Weber, A. L. Bioenergetics and life's origins. Cold Spring Harb. Perspect. Biol. 2, a004929 (2010).

2. Feller, G. Protein stability and enzyme activity at extreme biological temperatures. J. Phys. Condens. Matter 22, (2010).

3. Elias, M., Wieczorek, G., Rosenne, S. \& Tawfik, D. S. The universality of enzymatic ratetemperature dependency. Trends Biochem. Sci. 39, 1-7 (2014).

4. Garman, E. F. Radiation damage in macromolecular crystallography: what is it and why should we care? Acta Cryst 66, 339-351 (2010).

5. Fraser, J. S. et al. Hidden alternative structures of proline isomerase essential for catalysis. Nature 462, 669-673 (2009).

6. Keedy, D. A. et al. Crystal cryocooling distorts conformational heterogeneity in a model michaelis complex of DHFR. Structure 22, 899-910 (2014).

7. Keedy, D. A. et al. Mapping the conformational landscape of a dynamic enzyme by multitemperature and XFEL crystallography. Elife 4, 1-26 (2015).

8. Lang, P. T., Holton, J. M., Fraser, J. S. \& Alber, T. Protein structural ensembles are revealed by redefining X-ray electron density noise. Proc. Natl. Acad. Sci. 111, 237-242 (2014).

9. Henzler-Wildman, K. \& Kern, D. Dynamic personalities of proteins. Nature 450, 964-972 (2007).

10. Eisenmesser, E. Z., Bosco, D. A., Akke, M. \& Kern, D. Enzyme dynamics during catalysis. Science 295, 1520-3 (2002).

11. Pearson, A. R. \& Mehrabi, P. Serial synchrotron crystallography for time-resolved structural biology. Curr. Opin. Struct. Biol. 65, 168-174 (2020).

12. Chapman, H. N. X-Ray Free-Electron Lasers for the Structure and Dynamics of Macromolecules. Annu. Rev. Biochem. 88, 35-58 (2019).

13. Schmidt, M., Graber, T., Henning, R. \& Srajer, V. Five-dimensional crystallography. Acta Crystallogr. Sect. A Found. Crystallogr. 66, 198-206 (2010).

14. Schmidt, M. et al. Protein energy landscapes determined by five-dimensional crystallography. Acta Crystallogr. Sect. D Biol. Crystallogr. 69, 2534-2542 (2013).

15. Mehrabi, P. et al. Liquid application method for time-resolved analyses by serial synchrotron crystallography. Nat. Methods 16, 979-982 (2019).

16. Sanchez, S. \& Smiley, K. L. Properties of D-Xylose Isomerase from Streptomyces albus . Appl. Microbiol. 29, 745-750 (1975).

17. Makinen, M. W. \& Fink, A. L. Reactivity and cryoenzymology of enzymes in the crystalline state. Annual review of biophysics and bioengineering (1977). doi:10.1146/annurev.bb.06.060177.001505

18. Moffat, K. Time-resolved macromolecular crystallography. Annu Rev Biophys Chem 18, 309332 (1989).

19. Garman, E. F. \& Schneider, T. R. Macromolecular Cryocrystallography. J. Appl. Crystallogr. 30, 211-237 (1997).

20. Fischer, M. Macromolecular room temperature crystallography. Q. Rev. Biophys. 54, (2021).

21. Mehrabi, P. et al. The HARE chip for efficient time-resolved serial synchrotron crystallography. J. Synchrotron Radiat. 27, 360-370 (2020).

22. Schulz, E. C. et al. The hit-and-return system enables efficient time-resolved serial synchrotron crystallography. Nat. Methods 15, 901-904 (2018).

23. Sherrell, D. A. et al. A modular and compact portable mini-endstation for high-precision, high-speed fixed target serial crystallography at FEL and synchrotron sources. J. Synchrotron Radiat. 22, 1372-1378 (2015).

24. Mehrabi, P. et al. The HARE chip for efficient time-resolved serial synchrotron crystallography. J. Synchrotron Radiat. 27, 360-370 (2020).

25. Kiefersauer, R. et al. A novel free-mounting system for protein crystals: Transformation and improvement of diffraction power by accurately controlled humidity changes. J. Appl. Crystallogr. 33, 1223-1230 (2000).

26. Park, H. J., Tran, T., Lee, J. H., Park, H. \& Disney, M. D. Controlled dehydration improves the 
diffraction quality of two RNA crystals. BMC Struct. Biol. 16, 1-6 (2016).

27. Bowler, M. W., Montgomery, M. G., Leslie, A. G. W. \& Walker, J. E. Reproducible improvements in order and diffraction limit of crystals of bovine mitochondrial F1-ATPase by controlled dehydration. Acta Crystallogr. Sect. D Biol. Crystallogr. 62, 991-995 (2006).

28. Sanchez-Weatherby, J. et al. Improving diffraction by humidity control: a novel device compatible with X-ray beamlines. Acta Crystallogr. D. Biol. Crystallogr. 65, 1237-46 (2009).

29. Bowler, M. W. et al. Automation and experience of controlled crystal dehydration: Results from the European synchrotron hc1 collaboration. Cryst. Growth Des. 15, 1043-1054 (2015).

30. Sanchez-Weatherby, J. \& Moraes, I. Crystal dehydration inmembrane protein crystallography. Adv. Exp. Med. Biol. 922, 73-89 (2016).

31. Awad, W., Birkedal, G. S., Thunnissen, M. M. G. M., Mani, K. \& Logan, D. T. Improvements in the order, isotropy and electron density of glypican-1 crystals by controlled dehydration. Acta Crystallogr. Sect. D Biol. Crystallogr. 69, 2524-2533 (2013).

32. Atakisi, H., Moreau, D. W. \& Thorne, R. E. Effects of protein-crystal hydration and temperature on side-chain conformational heterogeneity in monoclinic lysozyme crystals. Acta Crystallogr. Sect. D Struct. Biol. 74, 264-278 (2018).

33. Klingl, S., Scherer, M., Stamminger, T. \& Muller, Y. A. Controlled crystal dehydration triggers a space-group switch and shapes the tertiary structure of cytomegalovirus immediateearly 1 (IE1) protein. Acta Crystallogr. Sect. D Biol. Crystallogr. 71, 1493-1504 (2015).

34. Perutz, B. Y. M. F. T H E COMPOSITION A N D S W E L L I N G P R O P E R T I E S of haemoglobin crystals. (1946).

35. Heras, B. et al. Dehydration converts DsbG crystal diffraction from low to high resolution. Structure 11, 139-145 (2003).

36. Heras, B. \& Martin, J. L. Post-crystallization treatments for improving diffraction quality of protein crystals. Acta Crystallogr. Sect. D Biol. Crystallogr. 61, 1173-1180 (2005).

37. Abergel, C. Spectacular improvement of X-ray diffraction through fast desiccation of protein crystals. Acta Crystallogr. Sect. D Biol. Crystallogr. 60, 1413-1416 (2004).

38. Huang, Q. \& Szebenyi, D. M. E. Improving diffraction resolution using a new dehydration method. Acta Crystallogr. Sect. Struct. Biol. Commun. 72, 152-159 (2016).

39. Mehrabi, P. et al. Liquid application method for time-resolved analyses by serial synchrotron crystallography. Nat. Methods 16, 979-982 (2019).

40. Kovalevsky, A. Y. et al. Metal Ion Roles and the Movement of Hydrogen during Reaction Catalyzed by D-Xylose Isomerase: A Joint X-Ray and Neutron Diffraction Study. Structure 18, 688-699 (2010).

41. Martiel, I., Müller-Werkmeister, H. M. \& Cohen, A. E. Strategies for sample delivery for femtosecond crystallography. Acta Crystallogr. Sect. D Struct. Biol. 75, 160-177 (2019).

42. Hekstra, D. R. et al. Electric-field-stimulated protein mechanics. Nature 540, 400-405 (2016).

43. Mo, F. \& Ramsskar, K. A sample cell for diffraction studies with control of temperature, relative humidity and applied electric field. J. Appl. Crystallogr. 42, 531-534 (2009).

44. Saunders, L. K. et al. An electric field cell for performing in situ single-crystal synchrotron Xray diffraction. .J. Appl. Crystallogr. 54, 1349-1359 (2021).

45. Garman, E. F. \& Schneider, T. R. Macromolecular Cryocrystallography. J. Appl. Crystallogr. 30, 211-237 (1997).

46. Kiefersauer, R. et al. A novel free-mounting system for protein crystals: Transformation and improvement of diffraction power by accurately controlled humidity changes. J. Appl. Crystallogr. 33, 1223-1230 (2000).

47. Sjögren, T. et al. Protein crystallography in a vapour stream: Data collection, reaction initiation and intermediate trapping in naked hydrated protein crystals. J. Appl. Crystallogr. 35, 113-116 (2002).

48. Sanchez-Weatherby, J. et al. Improving diffraction by humidity control: A novel device compatible with X-ray beamlines. Acta Crystallogr. Sect. D Biol. Crystallogr. 65, 1237-1246 (2009).

49. Baba, S. et al. A temperature-controlled cold-gas humidifier and its application to protein crystals with the humid-air and glue-coating method. J. Appl. Crystallogr. 52, 699-705 (2019). 
50. Wyckoff, H. W. et al. The Structure of Ribonuclease-S at 3.5 A Resolution. J. Biol. Chem. 242, 3984-3988 (1967).

51. Kurisu, G., Sugimoto, A., Kai, Y. \& Harada, S. A flow cell suitable for time-resolved X-ray crystallography by the Laue method. J. Appl. Crystallogr. 30, 555-556 (1997).

52. Helliwell, J. R. et al. Time-resolved and static-ensemble structural chemistry of hydroxymethylbilane synthase. Faraday Discuss. 122, 131-144 (2002).

53. Fuller, F. D. et al. Drop-on-demand sample delivery for studying biocatalysts in action at Xray free-electron lasers. Nat. Methods 14, 443-449 (2017).

54. Kovalevsky, A. Y. et al. Hydrogen location in stages of an enzyme-catalyzed reaction: timeof-flight neutron structure of D-xylose isomerase with bound D-xylulose. Biochemistry 47, 7595-7 (2008).

55. Collyer, C. A., Henrick, K. \& Blow, D. M. Mechanism for aldose-ketose interconversion by dxylose isomerase involving ring opening followed by a 1,2-hydride shift. J. Mol. Biol. 212, 211-235 (1990).

56. Pearce, N. M. et al. A multi-crystal method for extracting obscured crystallographic states from conventionally uninterpretable electron density. Nat. Commun. 8, (2017).

57. Pearce, N. M., Krojer, T. \& Von Delft, F. Proper modelling of ligand binding requires an ensemble of bound and unbound states. Acta Crystallogr. Sect. D Struct. Biol. 73, 256-266 (2017).

58. Schmidt, M. et al. Protein energy landscapes determined by five-dimensional crystallography. Acta Crystallogr. Sect. D Biol. Crystallogr. 69, 2534-2542 (2013).

59. Martin, R. W. \& Zilm, K. W. Preparation of protein nanocrystals and their characterization by solid state NMR. J. Magn. Reson. 165, 162-174 (2003).

60. White, T. A. et al. CrystFEL : a software suite for snapshot serial crystallography. J. Appl. Crystallogr. 45, 335-341 (2012).

61. McCoy, A. J. et al. Phaser crystallographic software. J. Appl. Crystallogr. 40, 658-674 (2007).

62. Adams, P. D. et al. Recent developments in the PHENIX software for automated crystallographic structure determination. J. Synchrotron Radiat. 11, 53-55 (2004).

63. Emsley, P. \& Cowtan, K. Coot: Model-building tools for molecular graphics. Acta Crystallogr. Sect. D Biol. Crystallogr. 60, 2126-2132 (2004).

64. Emsley, P., Lohkamp, B., Scott, W. G. \& Cowtan, K. Features and development of Coot. Acta Crystallogr. Sect. D Biol. Crystallogr. 66, 486-501 (2010).

65. Liebschner, D. et al. Polder maps: Improving OMIT maps by excluding bulk solvent. Acta Crystallogr. Sect. D Struct. Biol. 73, 148-157 (2017).

66. Schrödinger, LLC. The $\{P y M O L\}$ Molecular Graphics System, Version 1.8. (2015).

67. Schulz, E. C. et al. The hit-and-return system enables efficient time-resolved serial synchrotron crystallography. Nat. Methods 15, 901-904 (2018).

68. Mehrabi, P. et al. Serial femtosecond and serial synchrotron crystallography can yield data of equivalent quality: A systematic comparison. Sci. $A d v$. 7, eabf1380 (2021).

69. Zeldin, O. B., Gerstel, M., Garman, E. F. \& IUCr. RADDOSE-3D: time- and space-resolved modelling of dose in macromolecular crystallography. J. Appl. Crystallogr. 46, 1225-1230 (2013).

70. Dickerson, J. L., McCubbin, P. T. N. \& Garman, E. F. RADDOSE-XFEL : femtosecond timeresolved dose estimates for macromolecular X-ray free-electron laser experiments. J. Appl. Crystallogr. 53, 549-560 (2020).

71. Bury, C. S. \& Garman, E. F. RIDL : a tool to investigate radiation-induced density loss. $J$. Appl. Crystallogr. 51, 952-962 (2018).

72. Liebschner, D. et al. Macromolecular structure determination using X-rays, neutrons and electrons: Recent developments in Phenix. Acta Crystallogr. Sect. D Struct. Biol. 75, 861-877 (2019). 